\title{
Management Technologies and Development of the Company's Activities
}

\author{
D.G. Mustafaeva*, M.G. Mustafaev, and G.A. Mustafaev \\ North Caucasian Mining and Metallurgical Institute (State Technological University), Vladikavkaz \\ Russia
}

\begin{abstract}
The production process uses various management and control methods, which are the driving force for the development and improvement of production, and its efficiency. The most important elements of the control and control process are the object, method and executor of control, as well as regulatory documentation for control. Improving the competitiveness and demand of consumers is provided through a multi-level control system that allows to monitor the compliance of products with technological and regulatory requirements at all stages of production. Targeted process management functions in product creation are expressed through metrics that can be planned, monitored, and regulated, and are compatible with quality information transmitted from one level of management to another, and evaluated on each.
\end{abstract}

\section{Introduction}

Different management and control methods are used at all stages of the production process. Modern management and control methods for the company are the driving force for improving production, improving its efficiency and efficiency.

Currently, one of the main factors of the company's success in competition in the market is the quality of the products offered, as a consequence of the quality of not only the work performed in the production nature, but also the quality of its entire activities [1-9].

When creating a product, the development process is divided into stages, the transition from one stage to the next occurs after the completion of work at the current stage. Productcreating scheme includes: research, analysis, design, development, implementation, implementation, maintenance. Different management and control methods are used at all stages of the production process. Modern management and control methods for the company are the driving force for improving production, improving its efficiency and efficiency.

\section{Materials and methods}

The degree of customer satisfaction is the key to success, and therefore a steady demand for products. To succeed in the market, the manufacturer creates a quality system. For

\footnotetext{
* Corresponding author: dzhamilya79@yandex.ru
} 
manufacturers (enterprises) the presence of a quality system contributes to the improvement of production, efficiency. In addition, for the manufacturer, the availability of a quality system is an additional factor in implementing the development strategy and strengthening its position in the market.

The higher the quality of products, the greater the material capacity society has for further development and progress, is the basis for meeting both the production and personal needs of people. At the same time, the consumer basis of product quality is key.

Product quality measures to take into account the total product requirements and as an object of production or consumption, respectively, by manufacturers or consumers in its development, production and use in accordance with the needs. Therefore, the quality of the products is presented as a measure of its constructive and exploitative perfection, manifested in useful properties, the totality and importance of which reflects the existing at this stage requirements of society for it as a means of meeting certain needs.

Managing quality is the process of identifying the quality goals you need to achieve your organization's goals. Governance is defined as a common management function that determines the policies, objectives and responsibilities of quality, and implement them through quality planning, quality control, quality control within the quality system.

The main stages of quality management are:

- general quality management, which includes policy deployment, vendor engagement, process management, performance measurement, teamwork;

- quality assurance, including quality systems development, quality planning, failure and defect analysis, statistical process management;

- quality control, including quality guidance, process performance data, self-control, product testing, basic quality planning, use of basic statistics, document management;

- inspection, including sorting, corrective actions, determining the source of the discrepancy.

Inspection and quality control are retrospective, work in detection mode, trying to find the problems. The quality assurance and overall quality management are designed to reduce and avoid problems that can be used to improve.

The application of statistical methods in the planning and quality of production is a prerequisite for obtaining and processing information on the state of processes. Statistical analysis methods are the main tool for rapid and in-depth study of quality problems in an enterprise, which is based on the available data.

Applying statistical methods in quality planning involves measuring the necessary quality parameters, analyzing them and developing improvements in products and processes directly during technological operations, resulting in quality planning results:

- stability of output characteristics;

- reducing fixes and rework;

- minimizing the number of defects;

- increase in output;

- increase in profits;

- lower costs;

- reducing staff errors;

- increase the accuracy of the hardware setting;

- waste reduction;

- reducing equipment outages;

- efficient use of working hours;

- increased customer satisfaction with domestic and external consumers. 
Different methods and controls are used in the manufacture of products, depending on the object of control, controls, character and control method.

In the production process of product creation are used: control of materials and raw materials, components of parts and products, measurements and testing tools, equipment and equipment, control of the production system processes, skills of specialists, visual and instrumental.

The main elements of the control process are the object, method and executor of control, as well as regulatory documentation for control.

Instrumental quality control is a large part of the maintenance and repair processes of the equipment, based on technical measurements.

Measurements require activities that define the so-called measurement design. These include:

- analysis of the measuring task with the possible sources of errors;

- selecting measurement accuracy;

- choosing the number of measurements, method and measurement tools;

- formulating baseline data to calculate the margin of error;

- calculating individual constituents and total error;

- calculating accuracy and comparing them with selected metrics.

These questions should be reflected in the measurement methodology, but the degree of complexity of them should be adequate to the extent to which the original data is inaccurate. The types of measurements are determined by the physical nature of the measured value, the required measurement accuracy required, the required measurement speed, the conditions and the measurement mode, etc.

\section{Results and discussion}

To meet the challenge of increasing competitiveness and consumer demand, not only a high level of technical equipment is needed, but also a multi-level quality control system. A system that will allow at all stages of production with the help of modern control methods, to monitor compliance with processed raw materials and finished products technological and other requirements of standards. The main way to increase the competitiveness of products is to improve the efficiency of its life cycle processes. The effectiveness of lifecycle processes depends on the effectiveness of resource management.

Manufacturers are interested in improving the quality of their products, as it provides an opportunity to:

- to enter the market, expand its presence there and increase sales;

- to improve productivity by improving performance processes and reducing defectivity;

- reduce the risk of losses during the warranty period and for damages for the production of defective products;

- increase profits.

- Solving the problem of quality is the most important factor in improving living standards, its social and environmental safety. They are in the next dependency:

- economic - competitiveness;

- social - needs satisfaction, security;

- information - strengthening of market position;

- ecology - environmental health.

To focus the quality improvement process on the consumer, the manufacturer consistently takes the following steps:

- identify consumers; 
- identify consumer requirements;

- transform consumer requirements into technical delivery conditions;

- identify the stages in the workflow;

- choose the criteria for the effectiveness of the process;

- establish the possibilities of the process;

- assess the results;

- ensure consumer satisfaction.

The company's quality management system has a multifaceted nature of activities: constant training and retraining of personnel, working with consumers and suppliers, updating products and technologies, etc.

One of the most important elements of the quality management system is the product quality management mechanism, a collection of interconnected objects and management entities, the principles, methods and management functions used at different stages of the product lifecycle and quality management levels. The composition of the elements of this subsystem includes:

- subsystem of planning, control, regulation of product quality;

- implementation subsystem - standardization, testing, product certification and certification:

- subsystem providing - legal, logistical, personnel, organizational, technological, financial.

The principle of management is that the purpose of managing the processes of product creation and application must be expressed through indicators that can be used to plan, account, monitor and regulate quality management. However, these indicators should be compatible with quality information that is transmitted from one level to another and should be assessed at each level.

In order to develop and make decisions on management and maintain a successful development strategy, enterprises are implementing:

- continuous monitoring and systematic analysis of the environment, including the needs and expectations of its consumers, the competitive situation, new technologies, economic forecasts or sociological factors;

- assessing the capabilities of existing processes and available resources;

- identifying future resource and technology needs;

- updating your strategy and policies.

Strategies take into account activities such as consumer needs analysis, regulatory requirements, strengths and weaknesses, opportunities and threats.

Maintaining process parameters within certain limits ensures that operations are reproduced and their impact on the company's performance is quantified. The sustainable success of the company is achieved through its ability to meet the needs and expectations of its consumers and other stakeholders in a long-term and balanced manner.

Sustainable development management provides long-term economic efficiency in meeting environmental and social development requirements, and helps the company to make high-performance decisions aimed at continuous success for a long time. Improving the efficiency of production processes and improving the company's operations is achieved by applying a process and systemic approach to management - identifying, understanding the relationship of processes as a system, which contributes to the efficiency and efficiency of the enterprise in achieving its goals. 


\section{Conclusion}

The degree to which consumers meet the requirements is key to the company's success and the steady demand for products. The quality of the products is presented as a measure of its constructive and exploitative perfection, manifested in useful properties, the totality and importance of which reflects the established at this stage requirements of society to it as a means of meeting certain needs. Improving competitiveness and consumer demand is achieved by a high level of technical equipment and a tiered quality control system that allows all stages of production to monitor the production process and compliance with technological and regulatory standards. The targeted functions of product development management are expressed through indicators that can be planned, controlled and regulated, and compatible with quality information transmitted from one level of management to another, and can be evaluated on each.

\section{References}

1. D. Gharakhani, H. Rahmati, M.R. Farrokhi, A. Farahmandian, American Journal of Industrial Engineering, 1(3), 46 (2013)

2. J.C. Hallak, P.K. Schott, The Quarterly Journal of Economics, 126, 417 (2011)

3. A. Herrmann, F. Huber, C. Braunstein, International Journal of Production Economics. 66, 77 (2000)

4. M. Koilakuntla, V.S. Patyal, S. Modgil, P.A. Ekkuluri, Procedia Economics and Finance, 3, 55 (2012)

5. I. Sila, Journal of Operations Management, 25, 83 (2007)

6. A. Weckenmann, G. Akkasoglu, T. Werner, The TQM Journal, 27(3), 281 (2015)

7. J. Hanf, K.A. Dauttzenberg, Journal on chain and network science, 6(1), 79 (2006)

8. J.I. Jenssen, E. Nybakk, International journal of innovation management. 17(2), 27 (2013)

9. J.R. Lincoln, M.L. Gerlach, P. Takahashi, American sociological review, 57, 561 (1992) 